\title{
Correction of altered noradrenaline reactivity in essential hypertension by indapamide
}

\author{
M GRIMM, P WEIDMANN, A MEIER, G KEUSCH, \\ W ZIEGLER, Z GLÜCK, C BERETTA-PICCOLI
}

From the Medizinische Poliklinik, University of Berne, Switzerland

SUMMARY Fourteen patients with untreated mild to moderate essential hypertension had on average an abnormally high cardiovascular reactivity to exogenous noradrenaline and angiotensin II, while plasma noradrenaline, renin activity, exchangeable body sodium, and blood volume were normal. Treatment with a low dose of indapamide $(2.5 \mathrm{mg} /$ day $)$ for six weeks decreased blood pressure by $10 \%$ in these hypertensive patients but not in 13 normal control subjects. Plasma or blood volume and exchangeable sodium were not changed significantly; nevertheless, the latter, and body weight, tended to be decreased slightly. Though a mild reduction in extracellular sodium in both normal and hypertensive subjects appears possible, it may not per se fully explain indapamide's blood pressure-lowering effect in essential hypertension. Indapamide induced a mild decrease in angiotensin II pressor responsiveness in normal or hypertensive subjects, but a possible depressor influence from this change was probably antagonised by a concomitant pronounced increase in plasma renin activity. In hypertensive patients, the abnormally high noradrenaline ractivity was corrected by indapamide without an accompanying increase in endogenous plasma noradrenaline levels. Indapamide-induced changes in blood pressure correlated with those in noradrenaline pressor dose. It was concluded, therefore, that indapamide may decrease blood pressure in essential hypertension at least in part by lowering an abnormally high cardiovascular noradrenaline reactivity without causing an equivalent increase in adrenergic nervous activity.

The pathogenesis of essential hypertension is still incompletely understood and thus the selection of drugs for its treatment has been based largely on empirical guidelines. Recent studies have suggested that essential hypertension is associated with exaggerated cardiovascular reactivity to noradrenaline in the presence of normal or sometimes even somewhat high sympathetic and renin activity ${ }^{1-4}$ and a normal body sodium volume state. ${ }^{5} 6$

In consequence, an agent acting preferentially on vascular sensitivity should be of therapeutic interest. Indapamide ( $\mathrm{N}$ - (3-sulphamoyl-4-chlorobenzamido) 2-methyl indoline), a new antihypertensive compound, has been found, in vitro, to reduce the contractility of vascular smooth muscle cells in response to noradrenaline and angiotensin $\mathrm{II}^{78}$ The present study was undertaken to investigate the effects of indapamide on cardiovascular noradrenaline and angiotensin II reactivity and on various pressor factors in essential hypertension.

Received for publication 16 January 1981

\section{Subjects and methods}

Fourteen patients with borderline to moderate essential hypertension (10 men, four women, mean age $38 \pm 14 \mathrm{SD}$, range 18 to 62 years) and 13 normal healthy volunteers (nine men, four women, mean age $43 \pm 19 \mathrm{SD}$, range 22 to 66 years) were studied. All had not previously submitted to laboratory study. No patient had heart failure, coronary artery disease, a previous stroke, or a plasma creatinine above 115 $\mu \mathrm{mol} / 1(1.3 \mathrm{mg} / \mathrm{dl})$. None of the women were on oestrogen-containing oral contraceptive drugs. Antihypertensive drugs were withdrawn four weeks before the study. All the subjects, who had given their informed consent to the studies, were instructed to avoid very salty food and to refrain from adding salt to their food.

The clinical methods used in this study were given ethical approval by the Swiss National Science Foundation. Initially, subjects received a matched placebo, one tablet every morning for four weeks. 
The placebo was then replaced by active indapamide, one tablet $(2.5 \mathrm{mg})$ every morning, for six weeks. At the end of the placebo and indapamide phases the following were measured: 24 hour urinary sodium, potassium, catecholamine and creatinine excretion, plasma sodium, potassium (by flame photometer), and creatinine levels (by autoanalyser), haematocrit, blood volume, and exchangeable body sodium (by standard isotope dilution methods using ${ }^{131} \mathrm{~J}$-human serum albumin and ${ }^{24} \mathrm{Na}$, respectively) ${ }^{9}$; plasma renin activity (by radioimmunoassay), ${ }^{10}$ noradrenaline and adrenaline levels (by a radioenzymatic method), ${ }^{11}$ blood pressure and heart rate were determined in the morning after one hour of recumbency and again after one hour during which they were allowed to walk about the laboratory. Blood pressure was recorded with an automatic blood pressure recorder, Physiometrics SR2. Mean blood pressure was calculated as the sum of the diastolic pressure and one-third of the pulse pressure. The pressor reactivity to intravenously infused noradrenaline and angiotensin II is defined by convention as the inverse of its pressor dose $^{1}$ and was determined in the supine position after obtaining basal (preinfusion) plasma renin activity and noradrenaline levels. After 60 minutes of a slow infusion of $5 \%$ glucose, at least five basal blood pressure values were obtained and the glucose infusion was then replaced by a solution of noradrenaline in 5\% glucose, using a constant infusion pump. The rate of infused noradrenaline was increased stepwise every five to 15 minutes until mean blood pressure had stabilised for at least 10 minutes on each of two target levels, namely 10 to 15 and 25 to 35 $\mathrm{mmHg}$, respectively, above basal mean blood pressure. After an interval of 30 minutes, during which only $5 \%$ glucose was infused, an infusion of hypertensin (Ciba; Valine ${ }^{5}$ form of angiotensin II) in 5\% glucose was given in a similar way to reach two target levels of diastolic blood pressure, namely 5 to 10 and 15 to $25 \mathrm{mmHg}$ above basal diastolic blood pressure. The dose response curve was calculated, defining the pressor dose as the dose necessary to increase mean (noradrenaline) or diastolic (angiotensin II) blood pressure by $20 \mathrm{mmHg}$ and the threshold dose as the (extrapolated) dose to increase blood pressure by zero. ${ }^{12}$ Based on the previous demonstration of stable plasma noradrenaline concentration after five to 10 minutes of noradrenaline infusion at a given rate, ${ }^{13}$ the total plasma noradrenaline (NA) clearance $(\mathrm{Cl})$ was calculated by the formula

$$
\mathrm{Cl}\left(\frac{\text { litre }}{\min }\right)=\frac{\text { NA dose per minute }}{\begin{array}{l}
\text { corresponding plasma NA minus basal } \\
\text { plasma NA }
\end{array}}
$$

Each clearance value consisted of the mean of two to three single clearances obtained with lower and higher infusion rates.
For the $t$ test (always two-tailed) or regression analysis, the natural logarithm transformation of plasma renin activity, plasma aldosterone, noradrenaline, adrenaline, or threshold and pressor doses was used.

\section{Results}

Clinical and laboratory data are shown in Table 1. Six weeks of treatment with indapamide significantly decreased blood pressure by $10 \%$ in the hypertensive group, whereas it was unchanged in normal subjects. Mean body weight tended to decrease slightly in both groups $(-0.7$ and $-0.9 \mathrm{~kg}$, or -1 and $-1.3 \%$, respectively). Mean heart rate, plasma and blood volumes, plasma sodium and creatinine levels, and urinary sodium and potassium excretion rates were not altered significantly after six weeks on indapamide; total exchangeable sodium tended to be slightly lowered in the hypertensive and normal subjects $(-80 \mathrm{mmol}$ in both, or $-2 \cdot 8$ and $-2 \cdot 7 \%$, respectively), but these changes were also statistically not significant. Plasma potassium was decreased by an average of 0.5 to $0.6 \mathrm{mmol} / 1$.

Supine and upright plasma renin and catecholamine levels as well as 24 hour catecholamine excretion rates obtained during or at the completion of exchangeable sodium-blood volume measurements were comparable between untreated normal and hypertensive subjects, except for supine plasma adrenaline which tended to be slightly higher in the hypertensive group (Table 1). During indapamide treatment, supine and upright plasma renin activity was increased conspicuously $(\mathrm{p}<0.001)$. Plasma adrenaline was unchanged in the two groups. Mean plasma noradrenaline tended to be increased slightly, but this tendency reached statistical significance $(p<0.05)$ only in the hypertensive patients while they maintained the upright position. Plasma noradrenaline obtained in the supine position immediately before the noradrenaline infusion did not differ between untreated normal and hypertensive subjects and remained stable during treatment with indapamide (Table 2).

Patients with untreated essential hypertension, however, tended to have a lower noradrenaline pressor $(p<0 \cdot 1)$ and threshold dose $(p<0.001)$ than normal subjects (Table 2); and this alteration in the hypertensive patients was restored $(p<0.01)$ to normal by indapamide. Moreover, indapamideinduced changes in noradrenaline pressor dose and mean blood pressure were inversely correlated $(r=-0.62 ; p<0.05)$, (Fig.). In contrast, the pressor and threshold doses of infused noradrenaline in normal subjects were not influenced by indapamide. The slope of the noradrenaline dose-blood pressure 
Table 1 Basal values before and during indapamide treatment (mean $\pm S D$ )

\begin{tabular}{|c|c|c|c|c|}
\hline & \multicolumn{2}{|l|}{ Normal subjects } & \multicolumn{2}{|c|}{ Subjects with essential hypertension } \\
\hline & Placebo & Indapamide & Placebo & Indapamide \\
\hline \multicolumn{5}{|l|}{ Blood pressure } \\
\hline Supine $(\mathrm{mmHg})$ & $117 / 74 \pm 14 / 10$ & $117 / 75 \pm 14 / 9$ & $160 / 107 \pm 20 / 13$ & $143 \star / 96 \neq \pm 19 / 10$ \\
\hline Upright (mmHg) & $102 / 74 \pm 11 / 9$ & $101 / 73 \pm 15 / 13$ & $143 / 99 \pm 19 / 13$ & $126^{\star} / 91 \dagger \pm 15 / 11$ \\
\hline \multicolumn{5}{|l|}{ Heart rate } \\
\hline Supine (beats/min) & $62 \pm 11$ & $64 \pm 16$ & $70 \pm 11$ & $69 \pm 7$ \\
\hline Upright (beats/min) & $96 \pm 15$ & $92 \pm 15$ & $93 \pm 14$ & $94 \pm 18$ \\
\hline Body weight $(\mathrm{kg})$ & $69 \cdot 0 \pm 10 \cdot 4$ & $68 \cdot 1 \pm 10 \cdot 0 \dagger$ & $72 \cdot 8 \pm 12 \cdot 3$ & $72 \cdot 1 \pm 11 \cdot 6$ \\
\hline Plasma volume (litre) & $2 \cdot 59 \pm 0.51$ & $2.87 \pm 0.51 \dagger$ & $2 \cdot 52 \pm 0.60$ & $2 \cdot 48 \pm 0.35$ \\
\hline Blood volume (litre) & $4 \cdot 46 \pm 1 \cdot 09$ & $4 \cdot 80 \pm 1 \cdot 11$ & $4 \cdot 52 \pm 1 \cdot 02$ & $4 \cdot 28 \pm 0 \cdot 66$ \\
\hline Exchangeable sodium (mol) & $2.91 \pm 0.53$ & $2 \cdot 83 \pm 0.50$ & $2 \cdot 80 \pm 0 \cdot 41$ & $2 \cdot 72 \pm 0.35$ \\
\hline Plasma sodium $(\mathrm{mmol} / \mathrm{l})$ & $137 \pm 3$ & $137 \pm 2$ & $138 \pm 3$ & $138 \pm 2$ \\
\hline Potassium $(\mathrm{mmol} / \mathrm{l})$ & $4 \cdot 1 \pm 0 \cdot 2$ & $3.5 \pm 0.4 \varsigma$ & $4 \cdot 2 \pm 0 \cdot 3$ & $3 \cdot 7 \pm 0.5 \ddagger$ \\
\hline \multicolumn{5}{|l|}{ Renin activity (ng/ml per h) } \\
\hline Supine & $1 \cdot 5 \pm 1 \cdot 9$ & $3 \cdot 8 \pm 3 \cdot 8 \int$ & $1.5 \pm 0.9$ & $5 \cdot 2 \pm 5 \cdot 15$ \\
\hline Upright & $3 \cdot 3 \pm 3 \cdot 0$ & $9 \cdot 4 \pm 7 \cdot 4 \delta$ & $4 \cdot 8 \pm 5 \cdot 9$ & $17 \cdot 0 \pm 22 \cdot 6 \S$ \\
\hline \multicolumn{5}{|l|}{ Noradrenaline (ng/dl) } \\
\hline Supine & $22 \cdot 8 \pm 7 \cdot 5$ & $25 \cdot 9 \pm 8 \cdot 5$ & $21 \cdot 0 \pm 6 \cdot 3$ & $31 \cdot 9 \pm 15 \cdot 8$ \\
\hline Upright & $63 \cdot 8 \pm 23 \cdot 2$ & $78 \cdot 8 \pm 46 \cdot 9$ & $51 \cdot 1 \pm 14 \cdot 8$ & $76 \cdot 9 \pm 45 \cdot 3 \dagger$ \\
\hline \multicolumn{5}{|l|}{ Adrenaline (ng/dl) } \\
\hline Supine & $3 \cdot 1 \pm 1 \cdot 7$ & $3 \cdot 2 \pm 1 \cdot 8$ & $4 \cdot 8 \pm 2 \cdot 0^{\star}$ & $4 \cdot 2 \pm 1 \cdot 7$ \\
\hline Upright & $8 \cdot 4 \pm 6 \cdot 0$ & $7 \cdot 7 \pm 4 \cdot 7$ & $9 \cdot 1 \pm 4 \cdot 2$ & $7 \cdot 3 \pm 3 \cdot 3$ \\
\hline Urinary sodium $(\mathrm{mmol} / 24 \mathrm{~h})$ & $130 \pm 69$ & $131 \pm 70$ & $168 \pm 49$ & $182 \pm 80$ \\
\hline Potassium $(\mathrm{mmol} / 24 \mathrm{~h})$ & $59 \pm 21$ & $66 \pm 29$ & $71 \pm 24$ & $73 \pm 21$ \\
\hline Noradrenaline $(\mu \mathrm{g} / \mathrm{g}$ creatinine $) \| \star \star$ & $27 \cdot 2 \pm 11 \cdot 0$ & $28 \cdot 8 \pm 14 \cdot 4$ & $23 \cdot 7 \pm 10 \cdot 7$ & $28 \cdot 1 \pm 11 \cdot 1$ \\
\hline 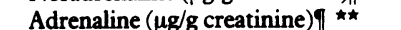 & $3 \cdot 8 \pm 2 \cdot 4$ & $2 \cdot 4 \pm 1 \cdot 6$ & $3 \cdot 9 \pm 2 \cdot 9$ & $2 \cdot 6 \pm 2 \cdot 4$ \\
\hline
\end{tabular}

$\star p<0.02$ versus corresponding value in normal subjects; $\uparrow \mathrm{p}<0.05, \ddagger \mathrm{p}<0.01, \S \mathrm{p}<0.001$ versus corresponding value under placebo conditions; $\| 1 \mu \mathrm{g}$ noradrenaline, $5.9 \mathrm{nmol}$; I $1 \mu \mathrm{g}$ adrenaline, $5.5 \mathrm{nmol}$; ${ }^{\star} 1 \mathrm{~g}$ creatinine, $8.8 \mathrm{mmol}$.

response curve and the total clearance of plasma noradrenaline did not differ between untreated normal and hypertensive subjects and were unchanged during treatment with indapamide.

The pressor dose of infused angiotensin II was lower $(\mathrm{p}<0.05)$ in the untreated hypertensive patients than in the normal control group (Table 2); the threshold dose and the slope of the dose-response curve were not significantly different. Indapamide slightly increased the angiotensin II pressor and threshold doses in both groups (statistically not significant), while the slope of the dose-pressor response curve was unchanged. Basal (preinfusion) plasma renin activity before treatment was com-

Table 2 Cardiovascular reactivity before and during indapamide treatment (mean $\pm S D$ )

\begin{tabular}{|c|c|c|c|c|}
\hline & \multicolumn{2}{|c|}{ Normal subjects } & \multicolumn{2}{|c|}{ Subjects with essential hypertension } \\
\hline & Placebo & Indapamide & Placebo & Indapamide \\
\hline \multicolumn{5}{|l|}{ (A) Noradrenaline infusion } \\
\hline Pressor dose (ng/kg per min)ף & $113 \pm 51$ & $114 \pm 50$ & $84 \pm 31^{\star}$ & $133 \pm 46$ \\
\hline Threshold dose (ng/kg per min) & $38 \pm 18$ & $34 \pm 18$ & $22 \pm 10 \pm$ & $36+178$ \\
\hline Slope & $19 \pm 6$ & $17 \pm 5$ & $15 \pm 5$ & $15 \pm 6$ \\
\hline Basal plasma noradrenaline $(\mathrm{ng} / \mathrm{dl})$ ฯ & $20 \cdot 7 \pm 10 \cdot 6$ & $16 \cdot 8 \pm 10 \cdot 2$ & $23 \cdot 5 \pm 10 \cdot 2$ & $25 \cdot 2 \pm 8 \cdot 4$ \\
\hline $\begin{array}{l}\text { Total plasma noradrenaline } \\
\text { clearance }(\text { litre/min })\end{array}$ & & & & \\
\hline Pressor dose (ng/kg per min) & $13 \pm 8$ & $18 \pm 13$ & $7 \cdot 7 \pm 4 \cdot 8 t$ & $11 \cdot 4+5 \cdot 8$ \\
\hline Threshold dose (ng/kg per min) & $1 \cdot 1 \pm 0.5$ & $2 \cdot 0 \pm 3 \cdot 1$ & $1 \cdot 5 \pm 1 \cdot 1$ & $2 \cdot 1 \pm 1 \cdot 2$ \\
\hline Slope & $9 \pm 3$ & $9 \pm 3$ & $13 \pm 6$ & $13 \pm 5$ \\
\hline Basal plasma renin activity ( $\mathrm{ng} / \mathrm{ml}$ per $\mathrm{h})$ & $1 \cdot 6 \pm 1 \cdot 1$ & $5 \cdot 2 \pm 4 \cdot 8 \|$ & $2 \cdot 2 \pm 1 \cdot 6$ & $4 \cdot 8 \pm 4 \cdot 18$ \\
\hline
\end{tabular}

* $p<0.1, \dagger p<0.05, \ddagger p<0.02$ versus corresponding value in normal subjects.

$\oint p<0.02, \| p<0.001$ versus corresponding value under placebo conditions.

If $1 \mathrm{ng}$ noradrenaline, $5.9 \mathrm{pmol}$. 


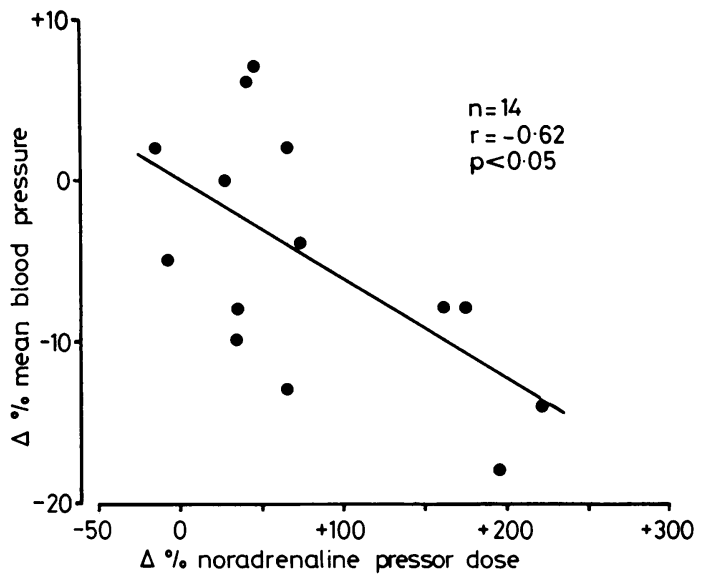

Fig. Relation between percentage changes in blood pressure and noradrenaline pressor dose during indapamide treatment in essential hypertension.

parable in the two groups and was much increased $(\mathrm{p}<0.001$ and $\mathrm{p}<0.02)$ during treatment with indapamide. No severe side effects were encountered during treatment.

\section{Discussion}

Indapamide is a sulphonamide derivative with both antihypertensive and diuretic properties, the latter probably by an action on the cortical diluting segment of the distal renal tubules. ${ }^{14}$ Since indapamide at a low dose of $2.5 \mathrm{mg} /$ day is an effective and practical treatment of hypertension, 81516 the same dose was also chosen for the present study.

The tendency for hypokalaemia to occur during indapamide treatment was probably a consequence of a state of secondary hyperaldosteronism ${ }^{17}$; it was of only mild degree and did not necessitate potassium supplements. After six weeks of indapamide treatment, blood pressure in our patients with mild to moderate hypertension was reduced by an average of $10 \%$. In contrast, it was unchanged in the normal subjects.

Treatment with low doses of indapamide had no statistically significant effects on total exchangeable body sodium, plasma or blood volume, plasma sodium, and urinary sodium excretion rates in either our normal or hypertensive subjects, or in 20 hypertensive patients reported by others. ${ }^{14}$ Nevertheless, considering the tendency for a slight parallel decrease in body weight $(0.9 \mathrm{~kg}$ in our normal and 0.7 in our hypertensive subjects) and total exchangeable sodium (about $-80 \mathrm{mmol}$ in both study groups), a mild extracellular sodium and fluid loss appears possible. Considering the unchanged blood pressure in the normal subjects treated with indapamide, this small variation of exchangeable sodium did not seem to exert a pronounced hypotensive effect. We accept that the available radioisotope techniques may not allow very subtle modifications of extracellular sodium-fluid volume contents and, perhaps more importantly, variations in small but relevant compartments such as the vascular smooth muscle cells to be detected. Whether and to what extent intracellular cardiovascular sodium metabolism may be altered in essential hypertension is still unknown. ${ }^{18}$ Our findings and those of others, ${ }^{15}$ however, are consistent with the possibility that factors other than extracellular sodium-fluid volume depletion per se may play an important part in the antihypertensive mechanism of indapamide.

Cardiovascular reactivity to angiotensin II tended to be slightly decreased by indapamide, as evidenced by a mild increase in pressor dose. On the other hand, plasma renin activity was significantly increased, as noted previously. ${ }^{17}$ These trends were similar in both the normal and hypertensive groups. Under physiological conditions, angiotensin II pressor responsiveness is inversely related to concomitant plasma renin activity, ${ }^{12} 19$ probably because of modulation of the number of free receptors accessible to circulating angiotensin. ${ }^{20}$ This mechanism may at least partly explain the blunting of the angiotensin pressor responsiveness during indapamide treatment. Furthermore, mild sodium depletion could possibly have played a contributory role. ${ }^{21}$ Whatever the exact underlying mechanism, a pressor influence from the pronounced increase in plasma renin activity may have antagonised any depressor action from the mild decrease in angiotensin II pressor responsiveness. ${ }^{17}$

The sympathetic effector-response axis in our hypertensive subjects under placebo conditions was characterised by abnormally high cardiovascular reactivity to noradrenaline in the presence of normal plasma noradrenaline, and adrenaline levels, and a normal plasma noradrenaline clearance, as noted previously. ${ }^{1-4} 13$ Indapamide had no significant influence on circulating catecholamines or noradrenaline clearance in both groups and on noradrenaline pressor reactivity in normal subjects. In contrast, it restored the altered pressor and threshold doses of infused noradrenaline in the hypertensive patients to normal.

This change in noradrenaline pressor responsiveness either could reflect a non-specific consequence of the decrease in basal (preinfusion) blood pressure; or may represent a distinct effect of indapamide which is itself responsible for the antihypertensive action of this agent. If the former explanation is correct the hypertensive patients should probably have a steeper slope of the noradren- 
aline dose-blood pressure response curve than the normal subjects in the untreated state; and this slope would have to be normalised by indapamide treatment. ${ }^{22}$ Since, however, the mean slope in our normal and hypertensive subjects was similar before indapamide and did not change after it we conclude that this drug may decrease blood pressure in essential hypertension by lowering an abnormally high noradrenaline pressor reactivity without causing an equivalent increase in adrenergic nervous activity. This conclusion is further supported by the existence of a significant correlation $(r=-0.62 ; p<0.05)$ between the indapamide-induced changes in blood pressure and the noradrenaline pressor dose.

Indapamide's beneficial effect on cardiovascular noradrenaline reactivity may be mediated by inhibition of inward calcium current in vascular smooth muscle cells. ${ }^{23}$ This may lower the availability of intracellular calcium which is necessary for excitation-contraction coupling. ${ }^{24}$ Other possible, though speculative mechanisms would be a reduction in the sodium or water content of the blood vessel walls $^{25}$ or stimulation of a "vasodilator" prostaglandin. ${ }^{17}$ Recently, an increase in the blood levels of the prostaglandin $I_{2}$-derivative 6 -keto- $P_{G F}$ was noted in hypertensive patients treated with the diuretic bendrofluazide. ${ }^{26}$ PGI may blunt the vasoconstrictive action of pressor hormones and is a potent stimulator of renin release ${ }^{27} 28$; these resemble the principal effects we found during treatment with indapamide.

This work was supported by a grant from the Swiss National Science Foundation.

\section{References}

1 Philipp T, Distler A, Cordes U. Sympathetic nervous system and blood-pressure control in essential hypertension. Lancet 1978; ii: 959-63.

2 Weidmann P, Keusch G, Flammer J, Ziegler WH, Reubi FC. Increased ratio between changes in blood pressure and plasma norepinephrine in essential hypertension. F Clin Endocrinol Metab 1979; 48: 727-31.

3 Weidmann P, Beretta-Piccoli C, Ziegler WH, Keusch G, Glück Z, Reubi FC. Age versus urinary sodium for judging renin, aldosterone and catecholamine levels: studies in normal subjects and patients with essential hypertension. Kidney Int 1978; 14: 619-28.

4 Weidmann P, Grimm M, Meier A, et al. Pathogenic and therapeutic significance of cardiovascular pressor reactivity as related to plasma catecholamines in borderline and established essential hypertension. Clin Exp Hypertens 1980; 2: 427-49.

5 Schalekamp MA, Lebel $M$, Beevers DG, Fraser $R$, Kolsters G, Birkenhäger WH. Body-fluid volume in low-renin hypertension. Lancet 1974; ii: $310-1$.
6 Weidmann P, Hirsch D, Beretta-Piccoli C, Reubi FC. Interrelations among blood pressure, blood volume plasma renin activity and urinary catecholamines in benign essential hypertension. Am $\mathcal{F}$ Med 1977; 62: 209-18.

7 Finch L, Hicks PE, Moore RA. The effects of indapamide on vascular reactivity in experimental hypertension. Curr Med Res Opin 1977; 5, suppl I: 44-54.

8 Uhlich E, Tröger C, Knoll W. Effects of indapamide in hypertensive patients and on experimental vascular reactivity. Curr Med Res Opin 1977; 5, suppl I: 71-8.

9 Weidmann P, De Châtel R, Schiffmann A, et al. Interrelations between age and plasma renin, aldosterone and cortisol, urinary catecholamines and the body sodium volume state in normal man. Klin Wochenschr 1977; 55: 725-33.

10 Sealey JE, Gerten-Banes J, Laragh JH. The renin system: variations in man measured by radioimmunoassay or bioassay. Kidney Int 1972; 1: 240-53.

11 Da Prada M, Zürcher G. Simultaneous radioenzymatic determination of plasma and tissue adrenaline, noradrenaline and dopamine within the femtomole range. Life Sci 1976; 19: 1161-74.

12 Chinn RH, Düsterdieck G. The response of blood pressure to infusion of angiotensin II: Relation to plasma concentrations of renin and angiotensin II. Clin Sci 1972; 42: 489-504.

13 Grimm M, Weidmann P, Keusch G, Meier A, Glück Z. Norepinephrine clearance and pressor effect in normal and hypertensive man. Klin Wochenschr 1980; 58: 1175-81.

14 Onesti G, Pitone J, Lowenthal DT, et al. Studies on the natriuretic effect and site of action of indapamide. Curr Med Res Opin 1977; 5, suppl I: 83-8.

15 Isaac $R$, Witchitz $S$, Kamoun A, Bagattini JC. A long-term study of the influence of indapamide on the exchangeable potassium and sodium pools in hypertensive patients. Curr Med Res Opin 1977; 5, suppl I: 64-70.

16 Kelly DA, Hamilton S. A placebo-controlled trial to evaluate the antihypertensive efficacy and acceptability of indapamide. Curr Med Res Opin 1977; 5, suppl I: $137-44$.

17 Weidmann P, Keusch G, Meier A, Glück Z, Grimm M, Beretta-Piccoli C. Effects of indapamide on the body sodium-volume state, plasma renin, aldosterone and catecholamines, and cardiovascular pressor sensitivity in normal and borderline hypertensive man. In: Velasco $M$, ed. Arterial hypertension. International Congress Series 496. Amsterdam, Oxford, \& Princeton: Excerpta Medica, 1980: 169-81.

18 Weidmann P. Recent pathogenic aspects in essential hypertension and hypertension associated with diabetes mellitus. Klin Wochenschr 1980; 58: 1071-89.

19 Weidmann P, Endres P, Siegenthaler W. Plasma renin activity and angiotensin pressor dose in hypertension. Correlation and diagnostic implications. $\mathrm{Br} \mathrm{Med} \mathcal{F}$ 1968; iii: $154-6$.

20 Thurston $\mathrm{H}$, Laragh JH. Prior receptor occupancy as a determinant of the pressor activity of infused angiotensin II in the rat. Circ Res 1975; 36: 113-7. 
21 Hollenberg NK, Chenitz WR, Adams DF, Williams GH. Reciprocal influence of salt intake on adrenal glomerulosa and renal vascular responses to angiotensin II in normal man. 7 Clin Invest 1974; 54: 34-42.

22 Folkow B. The haemodynamic consequences of adaptive structural changes of the resistance vessels in hypertension. Clin Sci Mol Med 1971; 41: 1-12.

23 Gargouil YM, Mironneau J. Effects of indapamide on excitation-contraction coupling in smooth muscle of the mammalian portal vein. Curr Med Res Opin 1977; 5, suppl I: 55-9.

24 Seidel CL, Bohr DF. Calcium and vascular smooth muscle contraction. Circ Res 1971; 28/29, suppl II: 88-95.

25 Tobian L. A viewpoint concerning the enigma of hypertension. Am f Med 1972; 52: 595-609.
26 Webster J, Hensby CN, Crowley K, Dollery CT. Circulating prostacyclin levels may be increased by bendrofuazide in patients with essential hypertension. Clin Sci Mol Med 1980; 59: 125s-8s.

27 McGiff JC, Quilley J. Prostaglandins, kinins and the regulation of blood pressure. Clin Exp Hypertens 1980; 2: $729-40$.

28 Weber PC, Siess W, Scherer B. Possible significance of renal prostaglandins in essential hypertension. Clin Exp Hypertens 1980; 2: 741-60.

Requests for reprints to Professor Peter Weidmann, Medizinische Universitätspoliklinik, Freiburgstrasse 3, 3010 Berne, Switzerland. 